\title{
LPS-Toll-Like Receptor-Mediated Signaling on Expression of Protein S and C4b-Binding Protein in the Liver
}

\author{
Tatsuya Hayashi' ${ }^{1,2}$ and Koji Suzuki ${ }^{1}$ \\ ${ }^{1}$ Department of Molecular Pathobiology, Mie University Graduate School of Medicine, Tsu-city, Mie 514-8507, Japan \\ ${ }^{2}$ Department of Biochemistry, Mie Prefectural College of Nursing, Tsu-city, Mie 514-0116, Japan \\ Correspondence should be addressed to Koji Suzuki, suzuki@doc.medic.mie-u.ac.jp
}

Received 20 March 2010; Revised 19 May 2010; Accepted 7 June 2010

Academic Editor: Keigo Machida

Copyright ( 2010 T. Hayashi and K. Suzuki. This is an open access article distributed under the Creative Commons Attribution License, which permits unrestricted use, distribution, and reproduction in any medium, provided the original work is properly cited.

\begin{abstract}
Protein S (PS), mainly synthesized in hepatocytes and endothelial cells, plays a critical role as a cofactor of anticoagulant activated protein $\mathrm{C}$ (APC). PS activity is regulated by C4b-binding protein (C4BP), structurally composed of seven $\alpha$-chains (C4BP $\alpha$ ) and a $\beta$-chain $(\mathrm{C} 4 \mathrm{BP} \beta)$. In this paper, based primarily on our previous studies, we review the lipopolysaccharide (LPS)-induced signaling which affects expression of PS and C4BP in the liver. Our in vivo studies in rats showed that after LPS injection, plasma PS levels are significantly decreased, whereas plasma C4BP levels first are transiently decreased after 2 to 12 hours and then significantly increased after 24 hours. LPS decreases PS antigen and mRNA levels in both hepatocytes and sinusoidal endothelial cells (SECs), and decreases $\mathrm{C} 4 \mathrm{BP}$ antigen and both $\mathrm{C} 4 \mathrm{BP} \alpha$ and $\mathrm{C} 4 \mathrm{BP} \beta$ mRNA levels in hepatocytes. Antirat CD14 and antirat Toll-like receptor (TLR) -4 antibodies inhibited LPS-induced NF $\kappa$ B activation in both hepatocytes and SECs. Furthermore, inhibitors of NF $\kappa$ B and MEK recovered the LPS-induced decreased expression of PS in both cell types and the LPS-induced decreased expression of C4BP in hepatocytes. These data suggest that the LPS-induced decrease in PS expression in hepatocytes and SECs and LPS-induced decrease in C4BP expression in hepatocytes are mediated by MEK/ERK signaling and NF $\kappa \mathrm{B}$ activation and that membrane-bound CD14 and TLR-4 are involved in this mechanism.
\end{abstract}

\section{Introduction}

Protein S (PS), a vitamin K-dependent plasma glycoprotein ( $\mathrm{Mr} 75,000)$, is a physiologically important regulator of blood coagulation, as patients with hereditary PS deficiency have severe thrombotic diseases [1-3]. In the blood coagulation system, PS is a cofactor of activated protein C (APC), which inactivates the blood coagulation factor $\mathrm{Va}$ and factor VIIIa [4-6] (Figure 1). PS may also directly inhibit the prothrombinase complex by binding to factor Va and factor Xa $[7,8]$. In human plasma, PS circulates in free form and in complex with $\mathrm{C} 4 \mathrm{~b}$-binding protein $(\mathrm{C} 4 \mathrm{BP})$, a protein of the classical complement pathway $[9,10]$. C4BP consists of seven $\alpha$ chains $(M r 70,000)$ and a $\beta$ chain $(M r 45,000)$, with the $\beta$ chain being important in complex formation with PS [11-13]. Both forms of PS are capable of binding to APC, but only the free form acts as a cofactor [14, 15] (Figure 2). Additionally, PS may promote phagocytosis of apoptotic cells by macrophages [16] and mediate neuroprotection via APC [17]. These observations suggest that PS has important functions in both blood coagulation and inflammation.

Human PS is mainly synthesized in hepatocytes, endothelial cells and megakaryocytes [18-20], and C4BP in hepatocytes [21]. Acquired decreased plasma PS levels have been associated with liver diseases [22], pregnancy [23], oral contraceptive use [24], sepsis-associated disseminated intravascular coagulation (DIC) [25], and systemic lupus erythematosus [26], and patients with these conditions have an increased incidence of thrombotic events. Decreased levels of free PS may also lead to thrombotic tendency; therefore, it is believed that increased levels of plasma C4BP, as found in type III PS deficiency, are a risk factor of thrombosis [27].

Previously, we demonstrated that PS acts as a cofactor for APC in rats, and that it forms a complex with rat C4BP, as in humans [28]. Studies in various species demonstrated that both humans and rats have the PS-C4BP complex in 


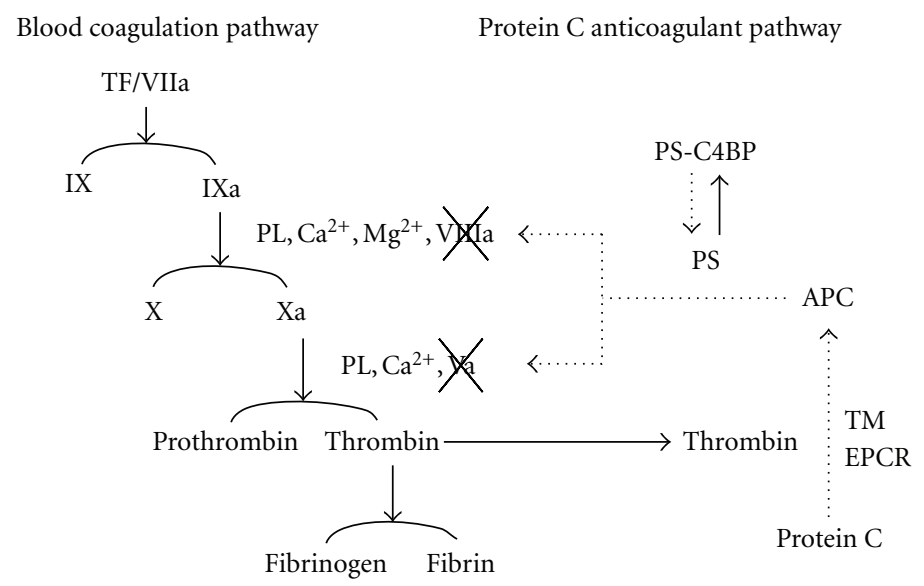

FIGURE 1: Blood coagulation pathway and protein C anticoagulant pathway. Thrombin, bound to thrombomodulin (TM), activates protein $\mathrm{C}$ which binds to endothelial protein C receptor (EPCR). Activated protein C (APC) inactivates coagulation factor Va (Va) and factor VIIIa (VIIIa) in the presence of protein S (PS). PS circulates in free form and in complex with C4b-binding protein (C4BP) in plasma, and the free form of PS plays a role as a cofactor of APC. TF: Tissue factor, PL: Phospholipids.

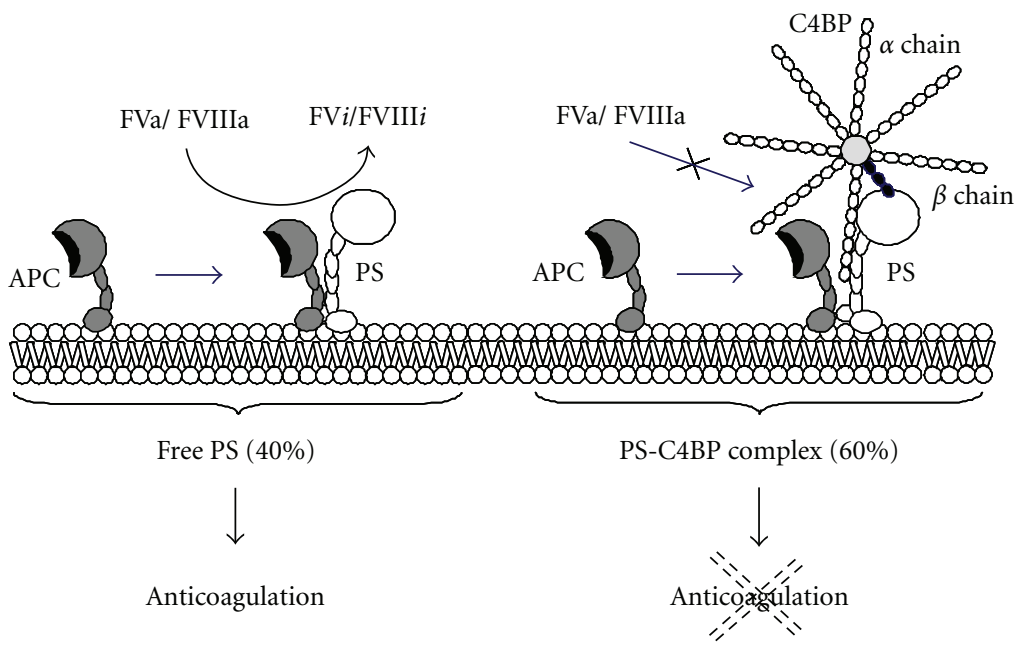

FIgure 2: Functions of PS and PS-C4BP complex. PS circulates in free form (about 40\%) and in complex form with C4BP (about 60\%) in plasma. C4BP is comprised of seven $\alpha$ chains and a $\beta$ chain, and PS binds to the $\beta$ chain. APC proteolytically converts factors Va and VIIIa (Va/VIIIa) into inactivated factors Va and VIIIa (Vi/VIII $i$ ) in the presence of free form PS, but not the complex form PS with C4BP.

plasma $[10,14,28,29]$; therefore, rats are considered to be the most appropriate animal to study the pathophysiological role of PS. In this paper, we describe changes in the plasma levels of PS and C4BP. We also evaluate the in vitro effect of LPS on PS and C4BP expression in hepatocytes and/or sinusoidal endothelial cells (SECs) isolated from rats and the LPS-mediated signaling that affects PS and C4BP expression in these cells.

\section{Effect of LPS on PS Expression In Vivo and In Vitro}

We showed that in a rat endotoxemia model [30, 31], prepared by intraperitoneal injection of LPS, the total PS level in plasma was significantly decreased while the free PS level was markedly decreased in plasma after LPS injection
(Figures 3(a) and 3(b)). APC cofactor activity of plasma isolated from rats 24 hours after LPS injection was also evaluated by activated partial thromboplastin time (APTT), suggesting that plasma obtained from rats 24 hours after LPS injection prolonged the APTT significantly less than plasma from nontreated rats (data not shown). These results suggest that LPS-induced reduction of plasma PS is a cause of thrombotic tendency in patients with sepsis. Thses results were consistent with the report by Hesselvik et al. that patients with sepsis have decreased plasma levels of PS, and that this is associated with thrombotic events [32]. In the liver, PS mRNA transiently decreased from 4 hours to 8 hours after LPS treatment and then returned to baseline levels; however, the plasma antigen level of PS did not recover concomitantly with the PS mRNA expression [30]. The detailed mechanism of this phenomenon is unclear, thus 


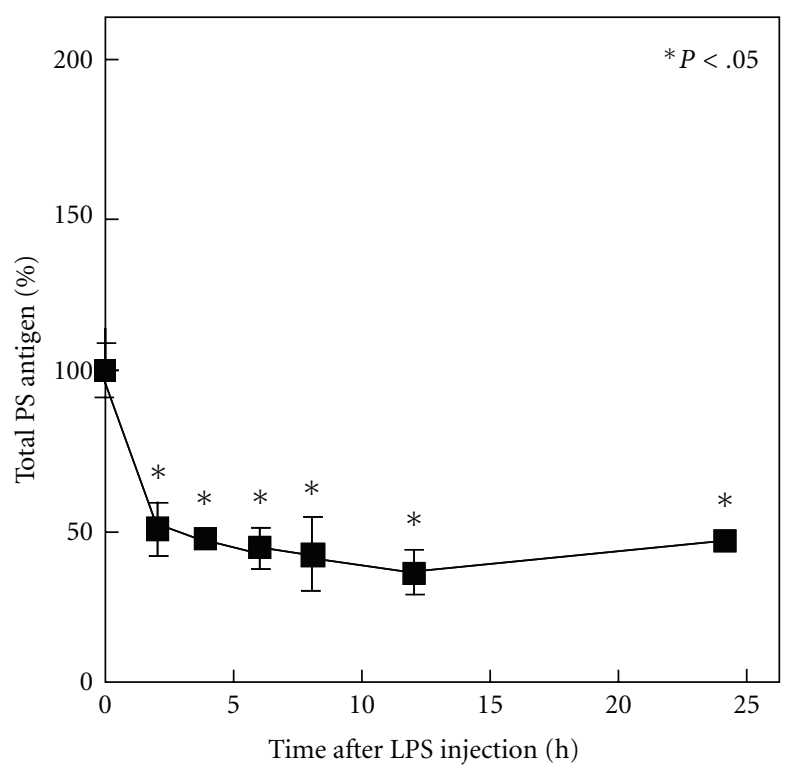

(a)

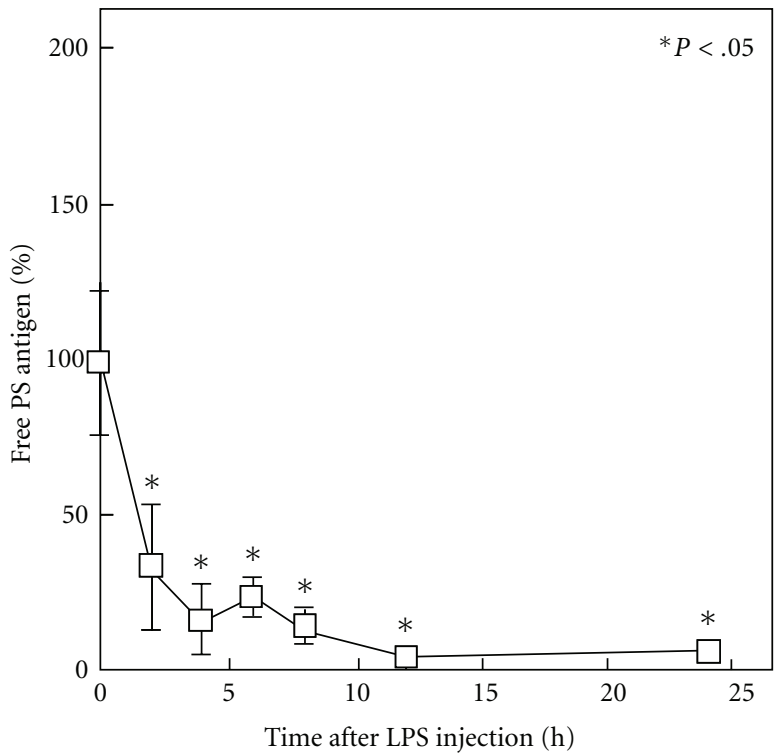

(b)

FIGURE 3: Changes in plasma levels of total PS and free PS in LPS-treated rats. Citrated plasma was obtained from three rats treated with LPS intraperitoneally $\left(2 \mathrm{mg} \cdot \mathrm{kg}^{-1}\right)$ at each time point to determine (a) plasma total PS antigen levels and (b) plasma free PS antigen levels, as described previously in [31]. Data are expressed as the mean \pm S.D. $(n=3) .{ }^{*} P<.05$ versus time 0 .

future investigations are needed. The in vitro studies using hepatocytes and SECs isolated from normal rats indicated that LPS dose-dependently decreased mRNA expression of PS in both cells, and these decreases occurred at the transcriptional level [30]. These data suggest that decreased plasma level of PS in LPS-treated rats is mainly due to reduced PS mRNA expression in both hepatocytes and SECs.

\section{Effect of LPS on C4BP Expression In Vivo and In Vitro}

It is reported that plasma C4BP levels are significantly increased in patients with severe infection and septic shock [32], but it is unknown whether C4BP expression in the liver is directly affected by LPS. We examined the effect of LPS on C4BP expression in vivo in the liver of rats and in vitro in isolated rat hepatocytes. We observed that LPS transiently decreased the plasma level of C4BP antigen with a maximum decrease between 4 hours and 6 hours, followed by a significant increase by 24 hours after LPS injection (Figure 4(a)) [31]. This result was consistent with the data that free PS was significantly decreased for 24 hours after LPS injection (Figure 3(b)). However, the PSC4BP complex level was not significantly changed within 24 hours after LPS injection (Figure 4(b)). The in vitro studies using hepatocytes isolated from normal rats indicated that LPS directly decreased both C4BP $\alpha$ and $\mathrm{C} 4 \mathrm{BP} \beta$ mRNA expression in hepatocytes [31]. These data suggest that the early decrease of plasma C4BP is caused by a direct effect of LPS. It is also reported that interleukin (IL)-6 increased C4BP expression in HepG2 cells [33], suggesting that in LPStreated rats the relatively late increase in the plasma level of
C4BP is caused by IL-6. It is reported that IL-6 also increased PS expression in HepG2 cells [34] and in rat hepatocytes [30]. However, it is unclear whether IL-6 is one of the causes of thrombotic tendency. To clarify this point we prepared IL-6-injected rats, and in vivo effect of IL-6 on plasma PS, C4BP and PS-C4BP complex level was examined. Our data indicated that both C4BP and PS-C4BP complex levels in plasma are increased until 8 hours after IL-6 injection, and then gradually decreased, and free PS level is decreased 24 hours after IL-6 injection, so that APC cofactor activity of plasma 24 hours after IL-6 injection is decreased as compared with nontreated rats (data not shown). These results suggest that IL- 6 causes thrombotic tendency by increasing C4BP expression in hepatocytes followed by increasing plasma PS-C4BP complex and decreasing plasma free PS level. These results also suggest that IL-6-induced reduction of free plasma PS is also the cause of thrombotic tendency in endotoxemia rats, and the major effect of IL-6 is increasing of C4BP expression in hepatocyte rather than increasing of PS expression in hepatocytes and SECs.

\section{Signal Transduction Pathway Involved in LPS-Induced Expression of PS in Hepatocytes and SECs and C4BP in Hepatocytes}

CD14 and TLR-4 are necessary for signal transduction induced by LPS in which LPS, bound to CD14, can interact with TLR-4 in the presence of myeloid differentiation protein-2 (MD-2) [35, 36]. It is known that induction by LPS on NF $\kappa$ B activation occurs via CD14 and TLR-4 in human endothelial cells [37], and mouse hepatocytes [38]. Recently, we showed that rat hepatocytes and SECs also 


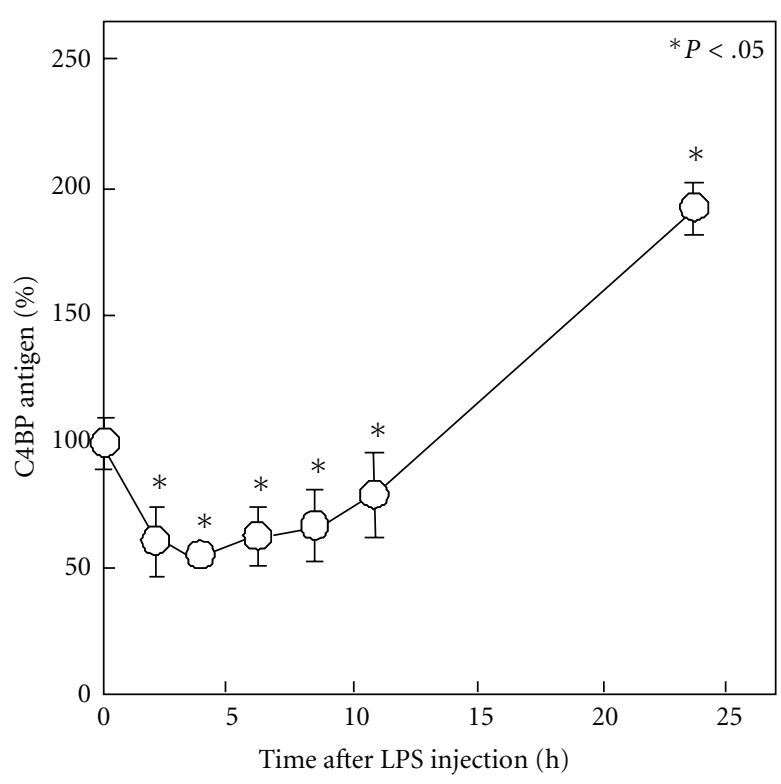

(a)

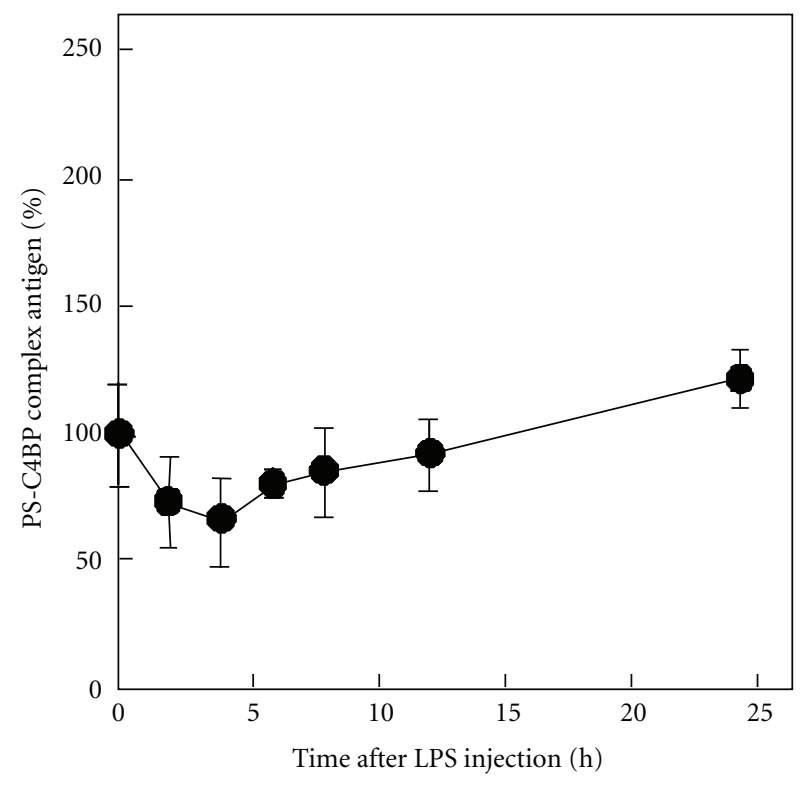

(b)

FIGURE 4: Changes in plasma levels of C4BP and PS-C4BP complex in LPS-treated rats. Citrated plasma was obtained from three rats treated with LPS intraperitoneally $\left(2 \mathrm{mg} \cdot \mathrm{kg}^{-1}\right)$ at each time point to determine (a) plasma C4BP antigen levels and (b) plasma PS-C4BP complex antigen levels, as described previously in [31]. Data are expressed as the mean \pm S.D. $(n=3) . * P<.05$ versus time 0 .

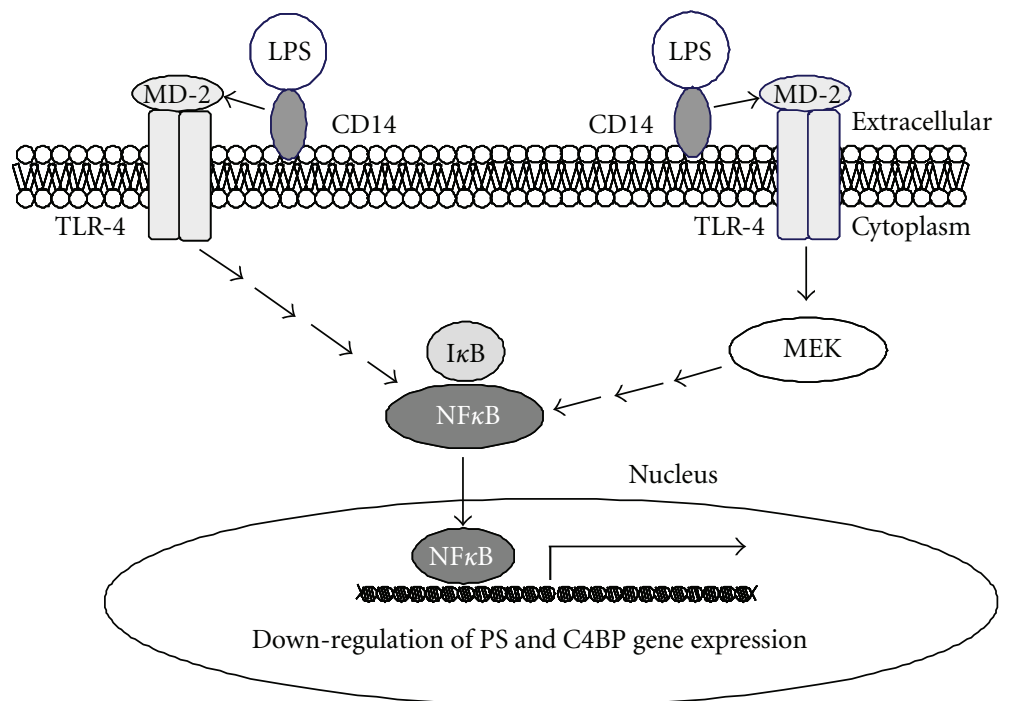

FIGURE 5: Mechanism of LPS-induced decreased expression of PS and C4BP in hepatocytes. LPS binds to membrane-bound CD14 and TLR-4, followed by activation of MEK/ERK and $\mathrm{NF} \kappa \mathrm{B}$. Activated $\mathrm{NF} \kappa \mathrm{B}$ interacts with the promoter regions of the $\mathrm{PS}$ and $\mathrm{C} 4 \mathrm{BP} \alpha$ and $\mathrm{C} 4 \mathrm{BP} \beta$ genes, leading to decreased PS expression in hepatocytes and SECs, and decreased C4BP expression in hepatocytes.

express CD14 and TLR-4 [30]. Further, gel mobility-shift assay indicated that anti-CD14 and anti-TLR-4 antibodies inhibit LPS-induced $\mathrm{NF} \kappa \mathrm{B}$ activation in both hepatocytes and SECs. These results suggest that LPS also induced NF $\kappa \mathrm{B}$ activation via CD14 and TLR-4 in both rat hepatocytes and SECs [30].

Furthermore, we found that a $\mathrm{NF} \kappa \mathrm{B}$ inhibitor blocked LPS-induced decreased expression of PS in both hepatocytes and SECs and the LPS-induced decreased C4BP $\beta$ expression in hepatocytes $[30,31]$, suggesting that $\mathrm{NF} \kappa \mathrm{B}$ activation is involved in the expression of PS and C4BP in hepatocytes and/or endothelial cells. These data also suggest that the rat $\mathrm{PS}, \mathrm{C} 4 \mathrm{BP} \alpha$ and $\mathrm{C} 4 \mathrm{BP} \beta$ gene promoters contain a $\mathrm{NF} \kappa \mathrm{B}$ consensus sequence. In addition, we found that a MEK inhibitor blocks LPS-induced reduction of PS expression in hepatocytes and SECs, and LPS-induced reduction of C4BP in hepatocytes $[30,31]$. These data are consistent with previous studies $[36,37]$, that LPS induces activation 
of the MEK/ERK pathway and NF $\kappa \mathrm{B}$ nuclear translocation in hepatocytes and endothelial cells. These findings suggest that $\mathrm{NF} \kappa \mathrm{B}$ activation and MEK/ERK pathway, but not the protein kinase C, JNK and p38 MAPK pathways, are linked to LPS-induced decreased PS expression in rat hepatocytes and SECs, and also linked to LPS-induced decreased C4BP expression in rat hepatocytes (Figure 5).

\section{Effect of Inflammatory Cytokines on PS and C4BP Expression in Hepatocytes and SECs}

LPS stimulates monocytes and endothelial cells to express various inflammatory cytokines [39, 40]. Among these inflammatory cytokines, tumor necrosis factor-alpha (TNF$\alpha$ ) decreased PS expression in rat SECs [30], and IL6 increased PS expression and $\mathrm{C} 4 \mathrm{BP} \beta$ expression, but not $\mathrm{C} 4 \mathrm{BP} \alpha$ expression, in rat hepatocytes [30, 31]. On the other hand, LPS directly decreased PS expression in human umbilical vein endothelial cells (HUVECs) (our unpublished observations). These findings are consistent with previous reports showing that TNF- $\alpha$ decreases PS expression in HUVECs [41] and that IL-6 increases PS expression in human hepatoma cell lines [34]. As described above plasma PS antigen and activity are decreased in LPStreated rats, and this suggests that both LPS and TNF- $\alpha$ induce decreased plasma PS levels, which causes thrombotic tendency in patients with sepsis. On the other hand IL-6 increased PS expression in hepatocytes, but this IL-6-induced increase of PS expression is not enough to compensate for LPS- and TNF- $\alpha$-induced decreased expression of PS in hepatocytes and/or endothelial cells. Furthermore, IL6 itself increased C4BP expression in rat hepatocytes, and the resulting decrease of free PS in plasma is thought to be the cause of thrombotic tendency. Overall, these results suggest that various cytokines which are induced by LPS in monocytes and endothelial cells induced thrombotic tendency in patients with sepsis. Recently, it was reported that IL-6-induced increased PS expression in HepG2 cells is regulated through the signal transducer and activator of transcription (STAT3) binding site, which is located in the $5^{\prime}$ flanking region of the human PS gene [42]. The mechanisms by which TNF- $\alpha$ specifically decreases PS expression in SECs and IL-6 specifically increases C4BP $\beta$ expression in hepatocytes are unknown. Further investigations are needed to elucidate the signal transduction pathway for IL-6 and TNF- $\alpha$ action in hepatocytes and SECs.

\section{Conclusion}

LPS directly decreases PS expression in hepatocytes and SECs and decreases C4BP expression in hepatocytes. Membranebound CD14 and TLR-4 mediate the LPS-induced activation of $\mathrm{MEK} / \mathrm{ERK}$ and $\mathrm{NF} \kappa \mathrm{B}$ and the activated $\mathrm{NF} \kappa \mathrm{B}$ interacts with promoter regions of the PS and $\mathrm{C} 4 \mathrm{BP} \alpha$ and $\mathrm{C} 4 \mathrm{BP} \beta$ genes. Moreover, LPS activates TLR-4 in monocytes to express IL-6 which stimulates expression of PS and C4BP in hepatocytes and/or endothelial cells. Our findings may be useful for the development of anticoagulation therapy involving PS and C4BP to regulate LPS-TLR-4-mediated activation of the $\mathrm{NF} \kappa \mathrm{B}$ and MEK system.

\section{Abbreviations

$\begin{array}{ll}\text { LPS: } & \text { Lipopolysaccharide } \\ \text { TLR: } & \text { Toll-like receptor } \\ \text { PS: } & \text { Protein S } \\ \text { C4BP: } & \text { C4b-binding protein } \\ \text { IL-6: } & \text { Interleukin-6 } \\ \text { PKC: } & \text { Protein kinase C } \\ \text { APC: } & \text { Activated protein C } \\ \text { JNK: } & \text { Jun kinase. }\end{array}$

\section{Acknowledgments}

The authors sincerely thank Drs. Hiroyuki Yuasa, Masane Kume, Koji Fujii, and Masashi Kishiwada who contributed to the studies on the LPS-mediated expressions of PS and C4BP in hepatocytes and/or SECs. This study was supported in part by a Grant-in-Aid for Scientific Research from the Ministry of Education, Culture, Sports, Science and Technology of Japan (18659280, 19390262, 21390292, and 22592396) and the Mie University COE-A project.

\section{References}

[1] T. Kamiya, T. Sugihara, K. Ogata, et al., "Inherited deficiency of protein $S$ in a Japanese family with recurrent venous thrombosis: a study of three generations," Blood, vol. 67, no. 2, pp. 406-410, 1986.

[2] P. C. Comp, R. R. Nixon, M. R. Cooper, and C. T. Esmon, "Familial protein $\mathrm{S}$ deficiency is associated with recurrent thrombosis," Journal of Clinical Investigation, vol. 74, no. 6, pp. 2082-2088, 1984.

[3] S. Gandrille, D. Borgel, H. Ireland et al., "Protein S deficiency: a database of mutations. For the Plasma Coagulation Inhibitors Subcommittee of the Scientific and Standardization Committee of the International Society on Thrombosis and Haemostasis," Thrombosis and Haemostasis, vol. 77, no. 6, pp. 1201-1214, 1997.

[4] B. Dahlback, "Protein S and C4b-binding protein: components involved in the regulation of the protein $\mathrm{C}$ anticoagulant system," Thrombosis and Haemostasis, vol. 66, no. 1, pp. 49-61, 1991.

[5] F. J. Walker, "Regulation of activated protein C by protein $\mathrm{S}$. The role of phospholipid in factor Va inactivation," The Journal of Biological Chemistry, vol. 256, no. 21, pp. 1112811131, 1981.

[6] G. A. Vehar and E. W. Davie, "Preparation and properties of bovine factor VIII (antihemophilic factor)," Biochemistry, vol. 19, no. 3, pp. 401-410, 1980.

[7] M. J. Heeb, R. M. Mesters, G. Tans, J. Rosing, and J. H. Griffin, "Binding of protein $\mathrm{S}$ to factor Va associated with inhibition of prothrombinase that is independent of activated protein C," The Journal of Biological Chemistry, vol. 268, no. 4, pp. 28722877, 1993.

[8] M. J. Heeb, J. Rosing, H. M. Bakker, J. A. Fernandez, G. Tans, and J. H. Griffin, "Protein S binds to and inhibits factor Xa," Proceedings of the National Academy of Sciences of the United States of America, vol. 91, no. 7, pp. 2728-2732, 1994. 
[9] B. Dahlback and J. Stenflo, "High molecular weight complex in human plasma between vitamin K-dependent protein S and complement component C4b-binding protein," Proceedings of the National Academy of Sciences of the United States of America, vol. 78, no. 4, pp. 2512-2516, 1981.

[10] B. Dahlback, "Purification of human C4b-binding protein and formation of its complex with vitamin K-dependent protein S," Biochemical Journal, vol. 209, no. 3, pp. 847-856, 1983.

[11] A. Hillarp and B. Dahlback, "Novel subunit in C4b-binding protein required for protein S binding," The Journal of Biological Chemistry, vol. 263, no. 25, pp. 12759-12764, 1988.

[12] B. Dahlback, C. A. Smith, and H. J. Muller-Eberhard, "Visualization of human C4b-binding protein and its complexes with vitamin $\mathrm{K}$-dependent protein $\mathrm{S}$ and complement protein C4b," Proceedings of the National Academy of Sciences of the United States of America, vol. 80, no. 11, pp. 3461-3465, 1983.

[13] Y. Härdig and B. Dahlbäck, "The amino-terminal module of the C4b-binding protein $\beta$-chain contains the protein $S$ binding site," The Journal of Biological Chemistry, vol. 271, no. 34, pp. 20861-20867, 1996.

[14] B. Dahlback, "Inhibition of protein Ca cofactor function of human and bovine protein $\mathrm{S}$ by $\mathrm{C} 4 \mathrm{~b}$-binding protein," The Journal of Biological Chemistry, vol. 261, no. 26, pp. 1202212027, 1986.

[15] J. Nishioka and K. Suzuki, "Inhibition of cofactor activity of protein S by a complex of protein S and C4b-binding protein. Evidence for inactive ternary complex formation between protein S, C4b-binding protein, and activated protein C," The Journal of Biological Chemistry, vol. 265, no. 16, pp. 90729076, 1990.

[16] H. A. Anderson, C. A. Maylock, J. A. Williams, C. P. Paweletz, H. Shu, and E. Shacter, "Serum-derived protein S binds to phosphatidylserine and stimulates the phagocytosis of apoptotic cells," Nature Immunology, vol. 4, no. 1, pp. 87-91, 2003.

[17] D. Liu, H. Guo, J. H. Griffin, J. A. Fernández, and B. V. Zlokovic, "Protein S confers neuronal protection during ischemic/hypoxic injury in mice," Circulation, vol. 107, no. 13, pp. 1791-1796, 2003.

[18] D. S. Fair and R. A. Marlar, "Biosynthesis and secretion of factor VII, protein $\mathrm{C}$, protein $\mathrm{S}$, and the protein $\mathrm{C}$ inhibitor from a human hepatoma cell line," Blood, vol. 67, no. 1, pp. 64-70, 1986.

[19] D. S. Fair, R. A. Marlar, and E. G. Levin, "Human endothelial cells synthesize protein S," Blood, vol. 67, no. 4, pp. 1168-1171, 1986.

[20] H. P. Schwarz, M. J. Heeb, J. D. Wencel-Drake, and J. H. Griffin, "Identification and quantitation of protein S in human platelets," Blood, vol. 66, no. 6, pp. 1452-1455, 1985.

[21] M. Kusada-Funakoshi, J. Sasaki, Y. Takada, T. Soji, and K. Arakawa, "Evidence that C4b-binding protein (proline-rich protein) is synthesized by hepatocytes," Biochemical Medicine and Metabolic Biology, vol. 45, no. 3, pp. 350-354, 1991.

[22] A. D’Angelo, S. Vigano-D'Angelo, C. T. Esmon, and P. C. Comp, "Acquired deficiencies of protein S. Protein S activity during oral anticoagulation, in liver disease, and in disseminated intravascular coagulation," Journal of Clinical Investigation, vol. 81, no. 5, pp. 1445-1454, 1988.

[23] P. C. Comp, G. R. Thurnau, J. Welsh, and C. T. Esmon, "Functional and immunologic protein $\mathrm{S}$ levels are decreased during pregnancy," Blood, vol. 68, no. 4, pp. 881-885, 1986.

[24] P. Quehenberger, U. Loner, S. Kapiotis et al., "Increased levels of activated factor VII and decreased plasma protein S activity and circulating thrombomodulin during use of oral contraceptives," Thrombosis and Haemostasis, vol. 76, no. 5, pp. 729-734, 1996.

[25] R. M. Madden, J. C. Gill, and R. A. Marlar, "Protein C and protein $\mathrm{S}$ levels in two patients with acquired purpura fulminans," British Journal of Haematology, vol. 75, no. 1, pp. 112-117, 1990.

[26] D. M. Keeling, S. J. Campbell, I. J. Mackie, S. J. Machin, and D. A. Isenberg, "Total and free protein $S$ in systemic lupus erythematosus," Thrombosis Research, vol. 60, no. 3, pp. 237240, 1990.

[27] P. Gracia de Frutos, P. Fuentes-Prior, B. Hurtado, and N. Sala, "Molecular basis of protein S deficiency," Thrombosis and Haemostasis, vol. 98, no. 3, pp. 543-556, 2007.

[28] F. Yasuda, T. Hayashi, K. Tanitame, J. Nishioka, and K. Suzuki, "Molecular cloning and functional characterization of rat plasma protein S," Journal of Biochemistry, vol. 117, no. 2, pp. 374-383, 1995.

[29] X. He and B. Dahlback, "Molecular cloning, expression and functional characterization of rabbit anticoagulant vitaminK-dependent protein S," European Journal of Biochemistry, vol. 217, no. 3, pp. 857-865, 1993.

[30] T. Hayashi, M. Kishiwada, K. Fujii et al., "Lipopolysaccharideinduced decreased protein $\mathrm{S}$ expression in liver cells is mediated by MEK/ERK signaling and NF $\kappa \mathrm{B}$ activation: involvement of membrane-bound CD14 and Toll-like receptor-4," Journal of Thrombosis and Haemostasis, vol. 4, no. 8, pp. 17631773, 2006.

[31] M. Kishiwada, T. Hayashi, H. Yuasa et al., "Regulatory mechanisms of C4b-binding protein (C4BP) $\alpha$ and $\beta$ expression in rat hepatocytes by lipopolysaccharide and interleukin-6," Journal of Thrombosis and Haemostasis, vol. 6, no. 11, pp. 1858-1867, 2008.

[32] J. F. Hesselvik, J. Malm, B. Dahlback, and M. Blomback, "Protein C, protein S, and C4b-binding protein in severe infection and septic shock," Thrombosis and Haemostasis, vol. 65, no. 2, pp. 126-129, 1991.

[33] D. J. Phillips, M. S. Novinger, B. L. Evatt, and W. C. Hooper, "TNF- $\alpha$ suppresses IL- $1 \alpha$ and IL- 6 upregulation of C4b-binding protein in HepG-2 hepatoma cells," Thrombosis Research, vol. 81, no. 3, pp. 307-314, 1996.

[34] W. C. Hooper, D. J. Phillips, M. Ribeiro, J. Benson, and B. L. Evatt, "IL-6 upregulates protein S expression in the HepG-2 hepatoma cells," Thrombosis and Haemostasis, vol. 73, no. 5, pp. 819-824, 1995.

[35] T. L. Gioannini and J. P. Weiss, "Regulation of interactions of Gram-negative bacterial endotoxins with mammalian cells," Immunologic Research, vol. 39, no. 1-3, pp. 249-260, 2007.

[36] H. Yang, D. W. Young, F. Gusovsky, and J. C. Chow, "Cellular events mediated by lipopolysaccharide-stimulated Toll-like receptor 4. MD-2 is required for activation of mitogenactivated protein kinases and Elk-1," The Journal of Biological Chemistry, vol. 275, no. 27, pp. 20861-20866, 2000.

[37] E. Faure, O. Equils, P. A. Sieling et al., "Bacterial lipopolysaccharide activates NF- $\kappa$ B through Toll-like receptor 4 (TLR4) in cultured human dermal endothelial cells. Differential expression of TLR-4 and TLR-2 in endothelial cells," The Journal of Biological Chemistry, vol. 275, no. 15, pp. 1105811063, 2000.

[38] S. Liu, D. J. Gallo, A. M. Green et al., "Role of Toll-like receptors in changes in gene expression and NF- $\kappa \mathrm{B}$ activation in mouse hepatocytes stimulated with lipopolysaccharide," Infection and Immunity, vol. 70, no. 7, pp. 3433-3442, 2002. 
[39] T. L. Kielian and F. Blecha, "CD14 and other recognition molecules for lipopolysaccharide: a review," Immunopharmacology, vol. 29, no. 3, pp. 187-205, 1995.

[40] A. Bierhaus, J. Chen, B. Liliensiek, and P. P. Nawroth, "LPS and cytokine-activated endothelium," Seminars in Thrombosis and Hemostasis, vol. 26, no. 5, pp. 571-587, 2000.

[41] W. C. Hooper, D. J. Phillips, M. J. Ribeiro et al., "Tumor necrosis factor- $\alpha$ downregulates protein $S$ secretion in human microvascular and umbilical vein endothelial cells but not in the HepG-2 hepatoma cell line," Blood, vol. 84, no. 2, pp. 483489, 1994.

[42] C. J. de Wolf, R. M. Cupers, R. M. Bertina, and H. L. Vos, "Interleukin-6 induction of protein $\mathrm{S}$ is regulated through signal transducer and activator of transcription 3," Arteriosclerosis, Thrombosis, and Vascular Biology, vol. 26, no. 9, pp. 2168-2174, 2006. 


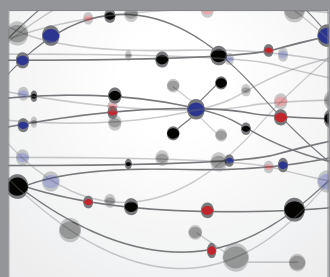

The Scientific World Journal
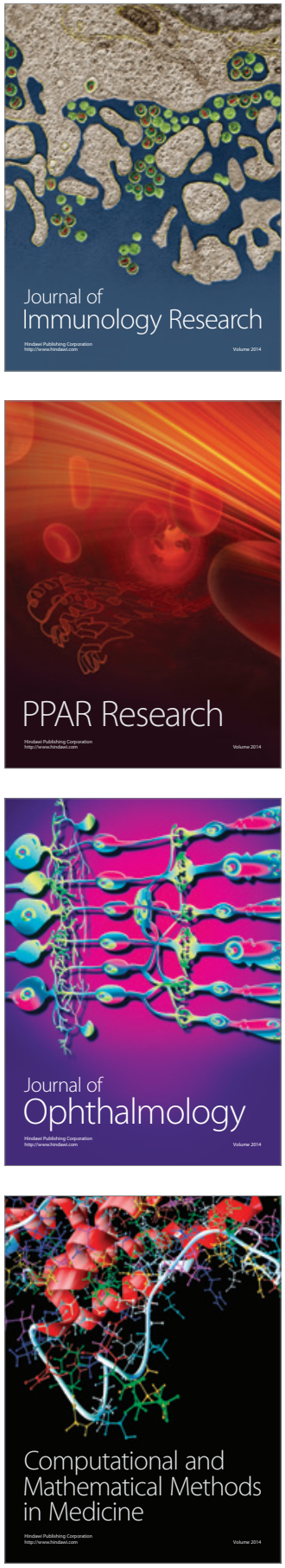

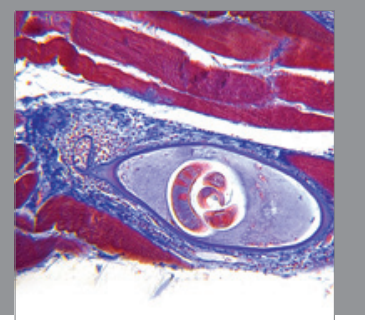

Gastroenterology

Research and Practice
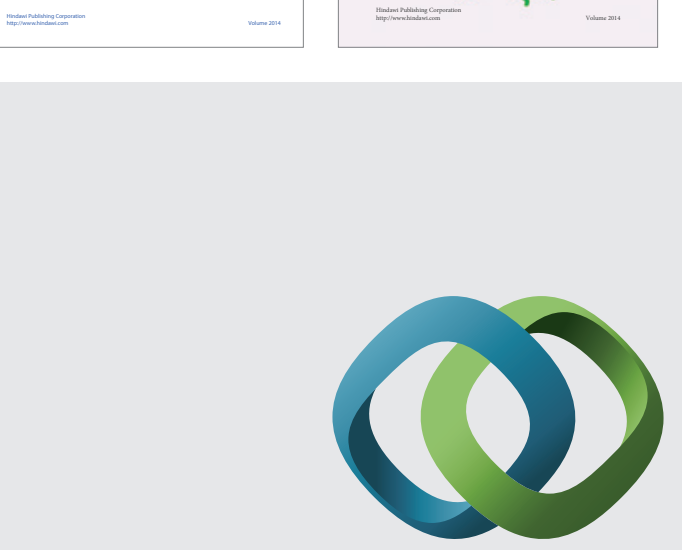

\section{Hindawi}

Submit your manuscripts at

http://www.hindawi.com
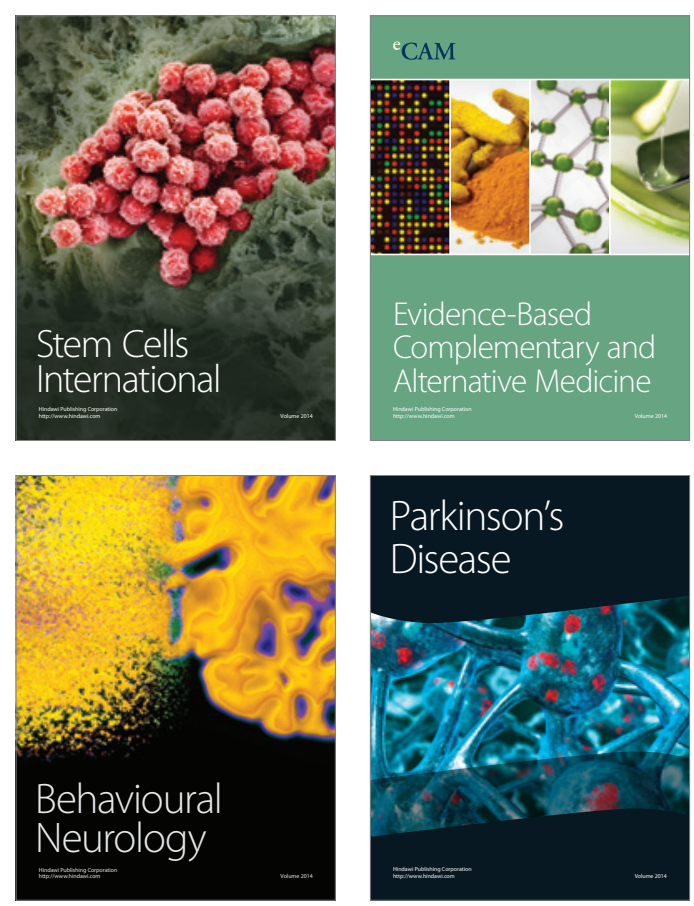

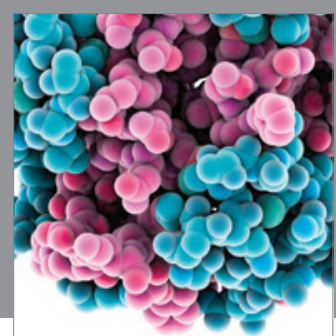

Journal of
Diabetes Research

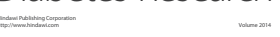

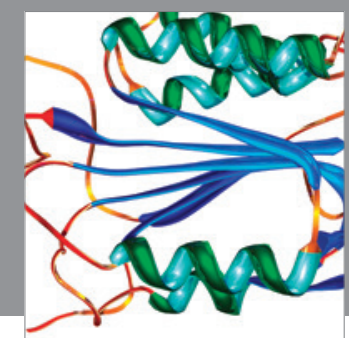

Disease Markers
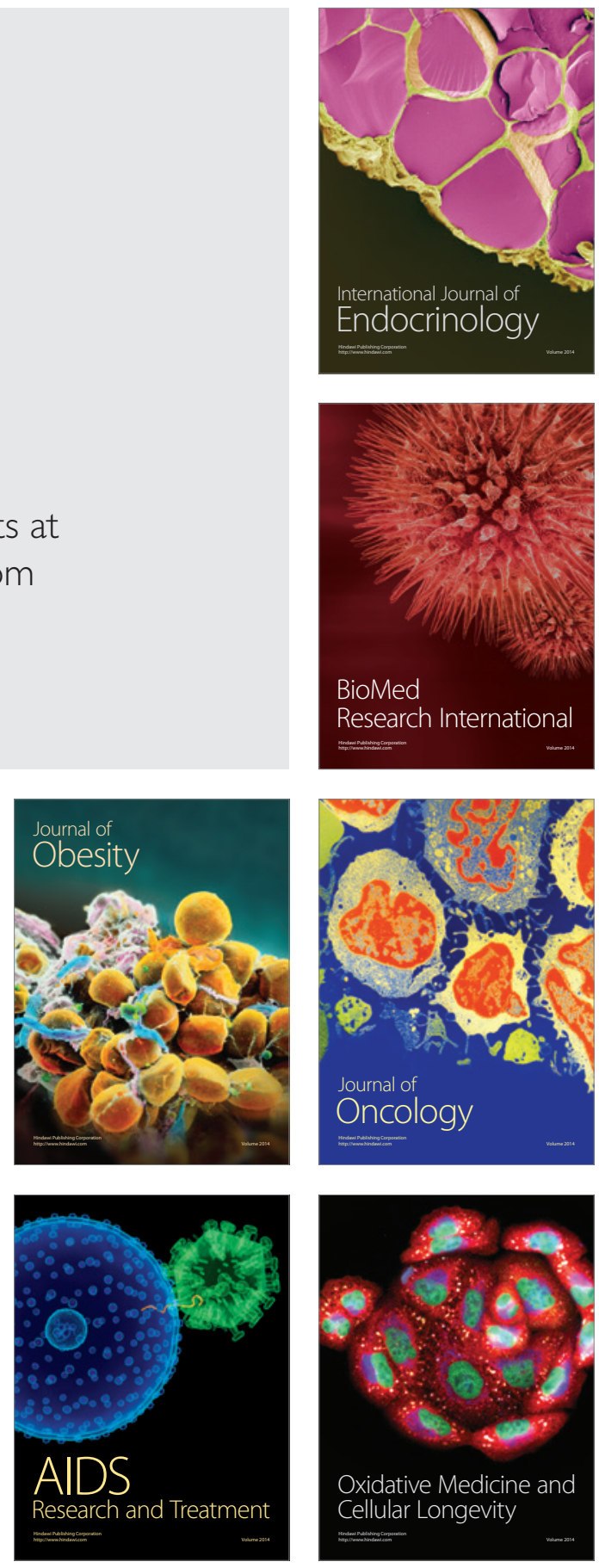